\title{
Causes of Aggressive Behaviour among Undergraduate Athletes in Ilorin Metropolis
}

\author{
Shuaib Abolakale Muhammed
}

Ph.D., Department of Counsellor Education, Faculty of Education, University of Ilorin, Nigeria, muhammed.sa@unilorin.edu.ng

Aggressive behaviour among sport athletes is one the most common problem that has devastating effects on athlete's career development. This study examined the causes of aggressive behavior among undergraduates' athletes in Ilorin metropolis and also investigated the influence of moderating variables of age, gender and sport type on athletes' aggressive behaviour. The research design adopted in this study was the descriptive survey. The population of the study comprised of all sport athletes in Ilorin metropolis. The respondents for the study were drawn using purposive sampling technique to select two hundred and fifty (250) athletes that participated in the study. Data was collected from the respondents with the use of the selfdesigned questionnaire tagged Causes of Aggressive Behaviour among Sport Athletes Questionnaire. That data obtained was analysed by using percentage, mean and ranking order analysis, Three-Way Analysis of Variance (ANOVA). The result of the study showed that sport athletes engaged in aggressive act when their friends are injured, when they are rough-handled, when they are bullied, when they feel threatened by their opponents, when their team complains about them. Results also revealed that there was no significant difference in the cause of aggressive behaviors among sport athletes in Ilorin metropolis based on age and gender, but a significant difference was found based on type of sport. Based on the findings of the study it was recommended among others that all athletes in Nigeria should be exposed to proper counselling to help them adjust better to their aggressive tendencies and also be more aware of the consequences of such actions to their career. They should also be educated on the adverse effect of aggressive behaviour.

Keywords: aggressive behaviour, sport athletes, undergraduates, athlete's career development, Ilorin Metropolis

\section{INTRODUCTION}

In sports, aggression is a characteristic that can have many negative as well as positive impacts on performance. Aggression is any form of behavior directed towards harming or injuring another person. Therefore it is a negative behaviour that can affect both the person showing aggression and people around him. Several authors have defined aggression to mean an act that is intended to cause harm to another person (Bernstein, Penner, Clarke-Stewart \& Roy, 2006) physical or verbal behavior intended to hurt someone (Myers, 2005) or as behavior that is intended to harm another individual (Brehm, Kassin \& Fein, 2005). Based on the above definitions, aggression refers to any act that hurts, harms or destroys which must be intended or deliberate. This presupposes that injuring someone accidentally or for the person's wellbeing cannot be construed as aggressive behavior.

Aggressive behavior is one of the components of the conduct disorder that consists of physical or verbal behavior that harm or threaten others which can be self-protective or self-destructive. There are different types of aggressive behavior; but commonly aggressive behaviors are categorized in terms of 
their function (Pederson, Bushman, Vasquez, \& Miller, 2008).The most predominant and influential classification is hostile aggression and instrumental aggression. Hostile aggression is when the main aim is to harm or injure the opponent. Instrumental aggression is when the main aim is to be nonaggressive but to win a possession (Morris, 2013). Hostile aggression is also called affective aggression; it is in nature uncontrolled, emotionally charged physical or verbal violence that causes physical injury or pain on the victim. In contrast, instrumental aggression or predatory aggressive behavior is controlled and purposeful non-physical violence that damage the victim's relationships with others (Pederson, Bushman, Vasquez, \& Miller, 2008).

Coulomb-cabagno and Rascle (2006) conducted a study looking at aggression in high level sport, and found that experienced athletes used more instrumental aggression in which they used to their advantage and that hostile aggression was less frequently used. Experienced athletes used self-control to help them with their aggression. More so, research on adolescent's aggressive behavior have reported that while boys tend to engage in physical aggression (hostile aggression) girls are more likely to express aggression in a relational sense (instrumental aggression). In a contrary, A more recent study conducted by Meysam, Batoul, Mehran, Mehdi, Zahra (2011) to determine the difference of aggression in male and female athlete and non-athlete students showed that there wasn't significant difference between male and female students in aggression, however differences between males and females in sub-factors such as invasion, violence and stubbornness were significant.

Similarly, Baccouche, Arous, Trabelsi, Masmoudi and Elloumi (2013) worked on the effect of gender and type of sport practiced on aggression and self-esteem in Tunisian athletes and found a negative correlation between self-esteem and aggression. The authors also found that males show more physical and verbal aggression than females. In contrast, females express more acts of anger and hostility than males. More so, Mashoodi, Mokthari \& Tajik (2013) compared aggression between young and adult athletes in individual or team sport and found a significant difference between the aggressive behavior of the young athletes and that of adult athletes, in such a form that the young athletes, whether male or female, were more aggressive that adult athletes did. The comparison of the aggressive behaviors of male and female athletes shows that male athletes are more aggressive than female athletes are. However, there is no difference between the aggression exhibited by both male and female adult athletes.

From the forgoing, it can be concluded that aggressive behaviour is a common phenomenon among sport athletes irrrespective of gender and age, however, the permissiveness of aggressive behaviors among sport athletes is a matter of great concern to many. This is because aggressive behavior can ruin the progress of the sports athletes' career and the nations sport development. Aggressive behaviors in sport are considered problematic in that they breed threat to peaceful co-existence of the athletes and coaches alike and constitute great danger for future if not quickly attended to. This study examined the causes of aggressive behavior among undergraduate athletes in Ilorin metropolis. Therefore the main question the study seeks to answer includes; what are ? The study also hypothesizes that:

1. There will be no significant differences in the causes of aggressive behavior among sport athletes in Ilorin metropolis based on gender, age and sport type.

\section{METHOD}

\section{Research Design}

The descriptive design of the survey type was adopted for the study. This type of design is concerned with describing, recording, analyzing and interpreting existing conditions as they naturally exist. The design was considered appropriate because it enabled the researcher to describe the view of sport athletes on the the causes of aggressive behaviours among sport athletes in Ilorin metropolis. 


\section{Participants}

The population of the study consisted of all sport athletes in Ilorin metropolis. Samples of 250 sport athletes were chosen for the study by using purposive and simple random sampling techniques. The purposive sampling technique was used to select athletes who are full time practitioners engaging in competitions in Ilorin metropolis; the athletes were purposely selected from University of Ilorin and Kwara state stadium complex. This is because most of them patronize these two places for their sport events.

\section{Data collection Tool}

The instrument used for data collection was a structured questionnaire tagged "Causes of Aggressive Behavior among Sport Athletes Questionnaire". The instrument has two major sections: ('A' and 'B'). Section 'A' contained the bio-data of the respondents while section 'B' contained the statements that were used to gather information on respondents view on the causes of aggressive behavior among athletes thereby enabling the researcher to answer the research questions and test the formulated hypotheses. Each statement of Section B was patterned after the four point scale of 'Strongly Agree', 'Agree', 'Disagree' and 'Strongly Disagree'. The instrument was validated by five lecturers in the Department of Counselor Education, University of Ilorin. The corrections of the experts were used to modify the questionnaire items before administering the final draft.

Also, the test-re-test method was used to ascertain the reliability of the instrument, 20 questionnaires were administered on 20 students who were not part of the study population, specifically from the university of Ilorin stadium complex. After 2 weeks, the same instrument was administered on the same group of students, the Pearson's Product Moment Correlation Coefficient was used to measure the reliability of the instrument and the coefficient value 0.63 was obtained. Based on this value, the instrument was adjudged reliable. The questionnaire forms were administered to the respondents by the researcher. The respondents filled forms immediately and collection was made on the spot to ensure $100 \%$ return rate.

Data Analysis

The data collected were analysed by using both descriptive and inferential statistical procedures. Percentage was used to describe the demographic data. Mean and rank order was used to answer the main research question while Three-way Analysis of Variance (ANOVA) was used to test all the null hypotheses at 0.05 alpha level. 


\section{FINDINGS}

Table 1

Distribution of Respondents by Gender, Age and Sport Type

\begin{tabular}{llll}
\hline S/N & Variables & Frequency & Percentage \% \\
\hline 1. & Gender & 127 & \\
& Male & 123 & 50.8 \\
& Female & 250 & 49.2 \\
& Total & & 100.0 \\
2 & Age & 92 & 36.8 \\
& 17-20 years & 137 & 54.8 \\
& 21-30 years & 21 & 8.4 \\
& 31 years \& above & 250 & 100.0 \\
& Total & & \\
3. & Type of Sport & 67 & 26.8 \\
& Football & 88 & 35.2 \\
& Basket Ball & 50 & 20.0 \\
& Track events & 45 & 18.0 \\
& Indoor Sport & 250 & 100.0 \\
\hline
\end{tabular}

Table 1 revealed that 127 (50.8\%) were Male whereas 123 (49.2\%) were female. Also 92 (36.8\%) of the participants were between 17-20 years old, 137 (54.8\%) were between 21-30 years old while 21 (8.4\%) were 31 years and above meaning that athletes between 21-30 years of age were represented more in the study. More so, 67 (26.8\%) were foot ball players $88(35.2 \%)$ of the participants were basketball players, 50 (20.0\%) engages in track events while $45(8.0 \%)$ engages in indoor sports.

Research Question: What are the causes of aggressive behavior among sport athletes in Ilorin Metropolis?

Table 2

Mean and Ranking Order Analysis on Causes of Aggressive Behavior Among Sport Athletes in Ilorin Metropolis.

\begin{tabular}{|c|c|c|c|}
\hline Item no & I get aggressive when & Mean & Rank \\
\hline 1 & my friends are injured & 3.07 & $1^{\text {st }}$ \\
\hline 9 & I am rough-handled & 2.89 & $2^{\text {nd }}$ \\
\hline 8 & I am bullied & 2.76 & $3^{\text {rd }}$ \\
\hline 10 & I feel threatened by my opponents & 2.72 & 4 th \\
\hline 6 & my team complains about me & 2.66 & 5 th \\
\hline 13 & I find it difficult to achieve my goals & 2.64 & 6 th \\
\hline 11 & a younger athlete disrespects me & 2.53 & 7 th \\
\hline 12 & I am anxious to win & 2.53 & 8 th \\
\hline 16 & I want to threaten my opponents & 2.52 & 9 th \\
\hline 3 & my team is losing & 2.52 & 10th \\
\hline 14 & my friends are aggressive and they encourage me to do so & 2.46 & 11 th \\
\hline 15 & my coach corrects me & 2.44 & 12 th \\
\hline 2 & when I drink alcohol & 2.39 & 13th \\
\hline 18 & officials are unjust & 2.38 & 14th \\
\hline 17 & the officials decision did not favor my team & 2.36 & 15 th \\
\hline 15 & Iwant to show of my strength & 2.35 & 16th \\
\hline 7 & I take psycho active drugs e.g. tramadol,cannabis & 2.22 & $17^{\text {th }}$ \\
\hline 19 & I get annoyed easily & 2.13 & 18th \\
\hline 4 & my team mates are trying to correct me & 2.09 & 19th \\
\hline 20 & I feel the opponents deserve to be bullied to achieve my aim & 1.95 & 20th \\
\hline
\end{tabular}


The table revealed that item 1, 9,8,10 and 6 ranked as the top 5 items. Item 1 which states that I get aggressive "when my friends are injured" ranked $1^{\text {st }}$ with a mean score of 3.07 , item 9 which states that I get aggressive "when I am rough-handled" ranked $2^{\text {nd }}$ with a mean score of 2.98 , item 8 which states that I get aggressive "when I am bullied" ranked $3^{\text {rd }}$ with a mean score of 2.76 . However, other items that ranked below 2.50 are not regarded as causes of aggressive behaviours among sport Athletes in Ilorin Metropolis. This finding of this study is in line with the submissions of other researches. For instance, Deater-Deckard, Dodge, Bates, \& Pettit (1996) found that most of the factors in adolescence that are known to lead to the development of aggression are environmental influences, such as family practices, neighborhood influences, socialization experiences, influence of the media, poverty, and gang membership. Also, Bartol, (2002) found that these individuals exhibit aggression due to fact that they are disliked and avoided by peers; they are neglected by parents and teachers; and are likely to fail in school, eventually dropping out and also transfer this aggression into all other aspects of their life.

Ho: there will be no significant differencin the causes of aggressive behaviour in sport athletes based on gender age and sport type

Table 3

Three way ANOVA showing differences on the respondents views on the Basis of gender, Age and Sport Type

Tests of Between-Subjects Effects

Dependent Variable:causes

\begin{tabular}{llllll} 
Source & $\begin{array}{l}\text { Type III Sum of } \\
\text { Squares }\end{array}$ & Df & Mean Square & F & Sig. \\
Corrected Model & $4648.556^{\mathrm{a}}$ & 21 & 221.360 & 2.431 & .001 \\
Intercept & 177072.582 & 1 & 177072.582 & 1.945 & .000 \\
Gender & 212.873 & 1 & 212.873 & 2.338 & .128 \\
Age & 306.212 & 2 & 153.106 & 1.682 & .188 \\
Sporttype & 771.498 & 3 & 257.166 & 2.825 & $* .040$ \\
gender* age & 253.944 & 2 & 126.972 & 1.395 & .250 \\
gender * sporttype & 1356.327 & 3 & 452.109 & 4.966 & $* .002$ \\
age * sporttype & 1205.490 & 6 & 200.915 & 2.207 & $* .043$ \\
gender * age* sporttype & 680.310 & 4 & 170.078 & 1.868 & .117 \\
Error & 20756.808 & 228 & 91.039 & & \\
Total & 640743.000 & 250 & & & \\
Corrected Total & 25405.364 & 249 & & & \\
\hline
\end{tabular}

a. R Squared $=.183$ (Adjusted R Squared $=.108)$

The result on the table revealed a calculated F-ratio of 2.338 (p value .128> .005) based on gender; Fratio 1.682 ( $\mathrm{p}$ value $.188>.005$ ) based on age and F- ratio 2.825 ( $\mathrm{p}$ value $.040<.005$ ) based on type of sports. This implies that there were no statistical significant differences in the causes of aggression among sport athletes in Ilorin Metropolis on the basis of gender, age but a significant difference was noted based on type of sport (i.e.indoor sports, football, basket ball and track events). The interaction effect between the moderating variables further revealed that there were no statistical interaction effect between gender and age i.e F- ratio 1.395 ( $\mathrm{p}$ value $.250>.005$ ). The table further showed that there are significant interaction effects between gender and sport types i.eF- ratio 4.996 (p value $.002<.005$ ); and between age and sport type i.e F- ratio 2.207 ( $\mathrm{p}$ value $.043<.005$ ). However, there was no 
significant interaction effect among gender, age and sport type i.e F- ratio 1.868 ( $\mathrm{p}$ value $.117>.005$ ). A further examination of the group difference was carried out using Duncan's Multiple Range Test (DMRT), a post-hoc test.

Table 4

Duncan's Multiple Range Test (DMRT) showing the magnitude of Difference in respondents view on the Cause of Aggressive Behaviour in Sport Athletes in Ilorin Metropolis based on Type of Sport.

\begin{tabular}{lllcc}
\hline Type of sport & Mean & N & Group & Duncan's grouping \\
\hline Indoor sports & 47.04 & 45 & 1 & A \\
Football & 48.30 & 67 & 1 & A \\
Basketball & 50.49 & 88 & 1 & A \\
Track Events & 52.14 & 50 & 2 & B \\
\hline
\end{tabular}

Table 4 above revealed that group 2 which are respondents engaging in track event contribute significantly to the difference noted in the result. The mean scores of group 2 (track events) are greater than the mean score of group 1 (indoor sports, Football and basketball). It can thus be concluded that both respondents who engages in track event contributed to the differences noted in the ANOVA table 3.The findings of this study are in line with other studies on aggressive behaviour. For instance Meysam, Batoul, Mehran, Mehdi and Zahra (2011) worked on the difference of aggression in male and female, athlete and non-athlete students and found that there wasn't significant difference between male and female students in aggression. However our result did not agree with findings of the study of Mashoodi, Mokthari \& Tajik (2013) who found a significant difference between the aggressive behavior of the young athletes and that of adult athletes, in such a form that the young athletes, whether male or female, have been more aggressive that adult athletes did. The comparison of the aggressive behaviors of male and female athletes shows that male athletes are more aggressive than female athletes are. The findings of the study is also in line with the study of Baccouche, Arous, Trabelsi, Masmoudi and Elloumi (2013) who found that practitioners of team sports are characterized by low self-esteem and high aggression and conversely for individual sports. They also found that males show more physical and verbal aggression than females. In contrast, females express more acts of anger and hostility than males.

The findings of this study may be attributed to the the fact that sport athlets in Nigeria may have similar experience of poor officiating which are usually the resultant effect of low technical know-how and lack of use of technologically driven facilitities that can facilitate fair judgement and other psychosocial factors such as favouratism and corruption. More so, the view on causes of aggressiveness among sport athletes of different age and gender are perhaps similar because they share the same culture of sporting, receive the same treatment from their trainers and organizers of sporting event. The view of sport athletes in track events which contributed to the difference noted in the result can also be attributed to the fact these players are not exposed to physical contact with other players from other teams or their opponents. Compared to athletes in foot ball, basket ball and other indor sports who are continuously exposed to physical contact with other players from other teams. The physical contact in form of touching can be interpreted in different ways by the players hence leading to an aggressive behavior.

\section{CONCLUSION}

Based on the results presented and the discussion, it can be concluded that sport athletes in Ilorin metropolis engaged in aggressive act when their friends are injured, when they are rough-handled, when they are bullied, when they feel threatened by their opponents, when their team complains about them among others. Also there was no significant difference in the cause of aggressive behaviors 
among sport athletes in Ilorin metropolis based on age and gender, but a significant difference was found based on type of sport.

\section{RECOMMENDATIONS}

Based on the study findings, its discussion and conclusion, the following recommendations were made:

1. Sport ahtletes should be trained on how to develop spirit of sportmanship in their sporting activities. This will assist them in controllling their aggresissive tendencies during sporting events.

2. Counselling centres and units should not be restricted to schools and hospitals.More centres and units should be established in sports and gymnasium complexes by both private government so that athletes are provided with appropriate counselling on issues that have to do with aggression an aggressive behavior management.

3. The research shows that athletes that are involved or participate in track or field events contributed significantly to the difference noted in the result based on sport type. Hence, more attention interms of counselling for agression management should be directed towards athletes that are involved in track events.

4. Counsellors need to provide relevant intervention programmes and supportive services that will cater for the needs of the athletes in teams that are aggressive and have some other forms of behaviour problems.

\section{REFERENCES}

Baccouche, M. A., Arous, I., Trabelsi, K., Masmoudi, L. \& Elloumi, A. (2013). Effect of gender and type of sport practiced on aggression and Self-esteem in Tunisian athletes. IOSR Journal of Humanities and Social Science, 8, (4) 74-80.

Bernstein, D.A., Penner, L.A., Clarke-Stewart, A. \& Roy, E. J. (2006).Psychology (7th ed.) Boston: Houghton Mifflin.

Brehm, S.S., Kassin, S. \& Fein, S. (2005). Social psychology.Boston: Houghton Mifflin.

Coulumb-cabagno, G. \& Rascle, O. (2006). Team sport players observed aggression as a function of Gender competitive, level and sport type. Journal of Applied Social Psychology, 36, 1980-2000

Mashoodi, S., Mokthari, P. \& Tajik, H. (2013).Comparison of the aggression of young and adult athletes in individual or team sports. European Journal of Experimental Biology, 3(1)661- 663

Meysam, R., Batoul A., Mehran, M., Mehdi S. \& Zahra, K. B. (2011). Determining the difference of aggression in Male \& Female, athlete and non-athlete students.Procedia -Social and Behavioral Sciences 30, $2264-2267$

Morris, P. (2013). Reconstructing project management reprised: A knowledge perspective. Journal of Project Management, 44, 6-23.

Myers, D.G. (2005). Social psychology (8th ed). New Delhi: McCraw Hill.

National Youth Violence Research Center (2002). Facts for teens aggression www.safeyouth.org. 
Pederson, W.C., Bushman, B.J., Vasquez, E.A. \& Miller, N. (2008).Kicking the (barking) dog effect: the moderating role of target attributes on triggered displaced aggression.Personality and Social Psychology Bulletin 34: 1382- 1395. 